\title{
n-6 Fatty acids and adipogenesis
}

\author{
Gérard Ailhaud
}

CNRS, ISDBC, Centre de Biochimie, Faculté des Sciences, Nice, France

Abstract

There is evidence from animal and human studies that changes in the balance of essential polyunsaturated fatty acids may alter the early stages of adipose tissue development. Consistent with these observations, cellularity of human adipose tissue from obese patients depends on the age of obesity onset. Under isoenergetic conditions, pups from wild-type mice mothers fed a linoleic acid (LA) diet were $40 \%$ heavier 1 week after weaning than those from mothers fed a LA/ $\alpha$-linolenic acid (LNA) diet, and the weight difference was maintained at the adult age. The LA-induced enhancement of fat mass was abolished in mice invalidated for the cell-surface prostacyclin receptor $\left(\mathrm{ip}^{-1-}\right.$ mice), demonstrating the critical role of arachidonic acid and the prostacyclin receptor in excessive adipose tissue development. Changes observed over recent decades in the fatty acid composition of dietary fats observed in breast milk and formula milk, i.e. an increase in LA with slight or no change in LNA content, in concert with a positive energy balance, may be responsible at least in part for the dramatic rise in the prevalence of childhood overweight and obesity. Since prevention of obesity appears critical to avoid difficult if not insurmountable health problems in the future, the composition of dietary lipids should be reconsidered from the very beginning of the food chain.

Keywords: adipose tissue; arachidonic acid; development; food; linoleic acid; milk

Abbreviations: ARA: arachidonic acid; C/EBP: CCATT/enhancer binding protein; EPA: eicosapentaenoic acid; DHA: docosahexaenoic acid; IP: prostacyclin receptor; LA: linoleic acid; LIF: leukaemia inhibitory factor; LNA: $\alpha$-linolenic acid; LCFA: long-chain fatty acid; PPAR: peroxisome proliferator activated receptor; PUFA: polyunsaturated fatty acid; WT: wild-type.

\section{Introduction}

$\mathrm{L}$ ongitudinal and cross-sectional studies in rodents and humans have shown a close relationship between hypercaloric diets, i.e. high-fat diets in most cases, and fat mass enlargement leading to overweight and obesity. It appears that, in addition to a positive energy balance, qualitative changes in the fatty acid composition of ingested fats have occurred, but possible effects of such changes have been so far disregarded. Recent evidence favours the possibility that changes in the balance of essential polyunsaturated fatty acids (PUFAs), i.e. linoleic acid-enriched diets and high linoleic acid (LA)/ $\alpha$-linolenic (LNA) ratios, enhance adipose tissue development during foetal life and infancy. These life periods show the highest adaptability and vulnerability to external factors. In contrast to saturated fat intake, which has been associated with an increased risk of coronary heart disease (1), little attention has been paid to potential effects of differences in dietary PUFAs and longchain fatty acids (LCFAs) in promoting adipose tissue development. The aim of this short review is to discuss this point.

\section{Non-equivalence of fatty acids acting as adipogenic hormones}

In preadipocytes, exogenous fatty acids acting as adipogenic hormones via peroxisome proliferator activated receptors (PPARs) are implicated in stimulating adipocyte formation (adipogenesis), thus providing a molecular link between excess of lipid intake, enhanced flux of fatty acids entering adipose tissue and increased fat mass (1).

Various key events take place during adipogenesis (Fig. 1). Up-regulation of the expression of CCAAT/enhancer binding protein $-\beta$ and $-\delta(\mathrm{C} /$ EBP- $\beta$ and $\mathrm{C} / \mathrm{EBP}-\delta$ ) leads to increased expression of PPAR- $\gamma$ (2), and gene invalidation has clearly shown the importance of these transcriptional factors in adipose tissue development (3-5). To activate the expression of $\mathrm{C} / \mathrm{EBP}-\beta$ and $\mathrm{C} / \mathrm{EBP}-\delta$ genes, at least two redundant cell-surface receptor/ ligand systems are functional in preadipocytes, i.e. 


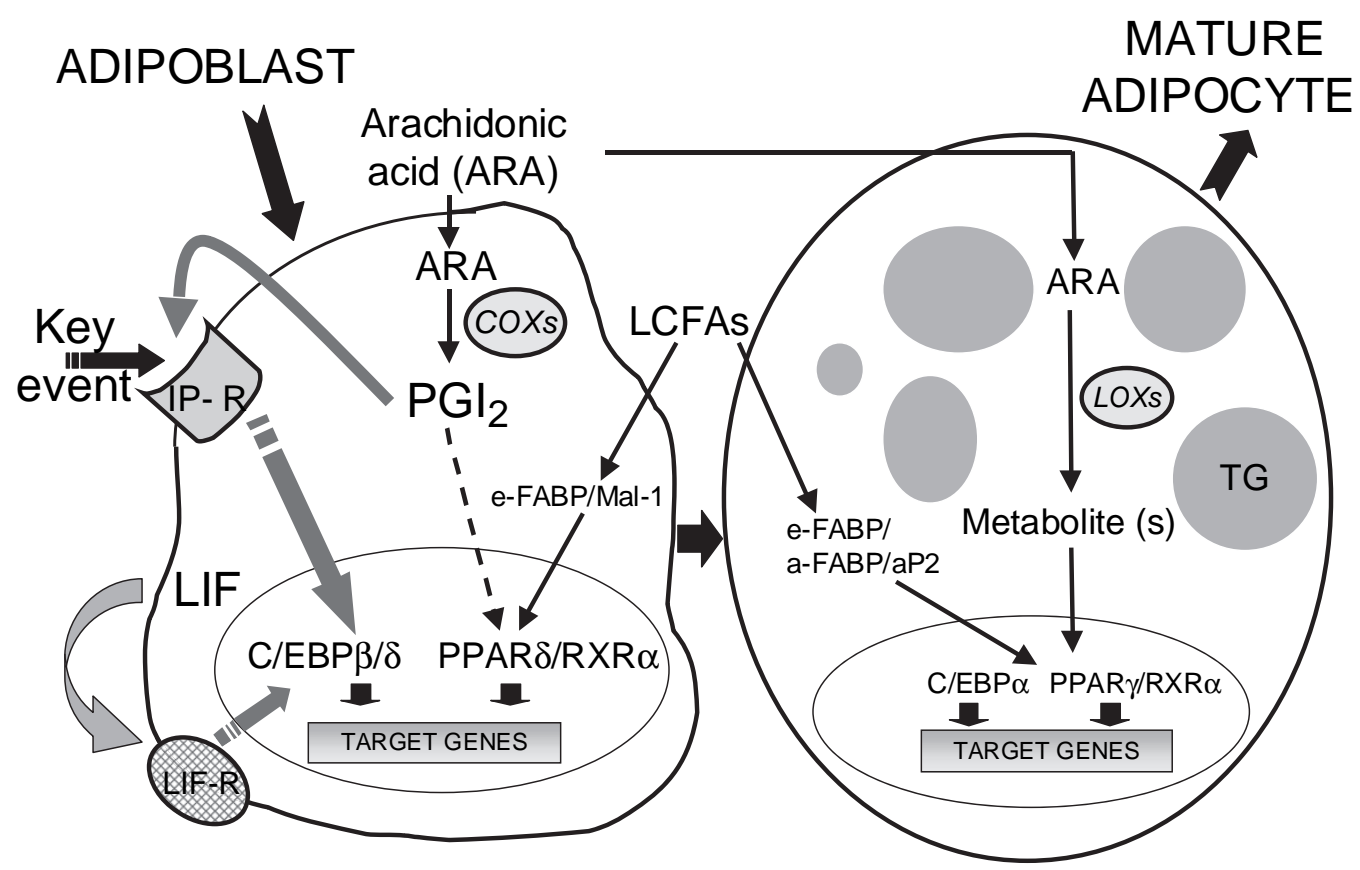

PREADIPOCYTE

IMMATURE ADIPOCYTE

Fig. 1. Redundant pathways and long-chain fatty acids (LCFAs) implicated in adipogenesis. At least two cell-surface receptor/ligand systems concur to up-regulate the expression of CCAAT/enhancer binding protein- $\beta(\mathrm{C} / \mathrm{EBP} \beta)$ and C/EBP $\delta$ [i.e. prostacyclin receptor (IP)/prostacyclin, and leukaemia inhibitor factor (LIF) receptor/LIF, and to promote adipogenesis. In preadipocytes, arachidonic acid (ARA) favours the synthesis of prostacyclin, which is then released. Thus, ARA via prostacyclin triggers a key event, plays a unique role in activating the protein kinase A pathway by means of IP, and enhances the differentiation process. Furthermore, prostacyclin is assumed to bind to peroxisome proliferator activated receptor- $\beta / \delta(\operatorname{PPAR} \beta / \delta)$. Other dietary LCFAs act as activators/ligands of PPAR $\beta / \delta$ and PPAR $\gamma$. Upon terminal differentiation, LIF is no longer produced. Production of prostacyclin and other prostaglandins ceases and is accompanied by reduced expression and loss of functional IP. In addition to ARA metabolites synthesized through cyclooxygenases (COXs) at early step(s), ARA metabolites synthesized through lipoxygenases (LOXs) as ligands of PPAR $\gamma$ are also implicated at later step(s). Epidermal (keratinocyte) fatty acid binding protein (e-FABP/Mall) in preadipocytes and also adipocyte fatty acid binding protein (a-FABP/aP2) in adipocytes are assumed to bind and transport LCFAs. TG: triglycerides.

prostacyclin receptor (IP)/prostacyclin and leukaemia inhibitory factor (LIF) receptor/LIF. Both ligands are secreted from preadipocytes and act externally in a paracrine/autocrine manner (6-8).

Prostacyclin synthesis takes place from arachidonic acid (ARA), the most naturally abundant longchain PUFA of the n-6 series, which is a metabolite of the LA pathway (9-11). Antibodies added externally directed against prostacyclin strongly diminish the adipogenic effect induced by ARA. Of the other natural fatty acids (saturated, monounsaturated and other PUFAs), including the isomer of ARA of the n-3 series, only ARA triggers cyclic adenosine monophosphate (cAMP) production through prostacyclin production and activates, via the IP receptor, the protein kinase pathway, which regulates in part the expression of C/EBP- $\beta$ and $\mathrm{C} / \mathrm{EBP}-\delta$. Eicosapentaenoic acid (EPA) and to a lesser extent docosahexaenoic acid (DHA), although inactive as cAMP-elevating agents, inhibit the stimulatory effect of ARA on cAMP production (12). The short-term intracellular production of cAMP and the long-term adipogenic effect, both triggered by ARA, are blocked by cyclooxygenase inhibitors (9). Prostacyclin, in the form of its stable analogue (carba)prostacyclin, mimics both the short- and long-term stimulatory effect of ARA (10), as shown in both rat and human primary preadipocytes $(11,13)$.

Several additional observations demonstrate that prostacyclin arising from ARA metabolism is a potent adipogenic hormone. Three features of such effects are particularly important: (i) it is active within a critical temporal window, i.e. at the precursor cell stage only $(11,13)$; (ii) through activation of the cell-surface receptor IP and the protein kinase A pathway, it rapidly up-regulates the expression of the early transcription factors $\mathrm{C} /$ EBP- $\beta$ and $C / E B P-\delta$, which in turn up-regulate the expression of PPAR- $\gamma$ (6); and (iii) exposure of 
white adipose tissue to (carba)prostacyclin ex vivo and in vivo triggers the formation of new adipocytes within a few hours (14).

Based on these data, nutritional experiments have been performed to investigate whether a LA-enriched diet modulates fat mass through an increased flux of LA metabolites, e.g. ARA, and whether LNA counteracts this effect. Under isoenergetic conditions, comparative experiments were performed with wild-type (WT) mice and mice invalidated for the cell-surface prostacyclin receptor ( ip $^{-1-}$ mice). These studies showed that (i) pups from WT mothers fed an LA diet are $40 \%$ heavier 1 week after weaning than those from mothers fed an LA/LNA diet; the ratios of n-6 PUFAs versus n3 PUFAs were 59/1 for the LA diet and 2/1 for the LA/LNA diet, respectively; (ii) the weight difference between mice fed LA and those fed LA/LNA diets is maintained at the adult age; and (iii) the LAinduced enhancement of fat mass is abolished in $i p^{-1-}$ mice, demonstrating the critical role of ARA and the prostacyclin receptor in excessive adipose tissue development (12). These studies show that PUFAs of the n-6 and n-3 series are not equipotent in promoting adipogenesis in vitro and adipose tissue development in vivo.

\section{Relevance to childhood and adult obesity}

Considering the adipogenic role of LA-enriched diet and the counteracting effect of LNA in rodents, one key question to be addressed in humans is whether the balance of PUFAs has changed over the decades such as it could favour excessive adipose tissue development. With respect to childhood, comparative US data between the National Health and Nutrition Survey II (1976-1980) and the NAHNES III (1988-1994) indicate that the adiposity indices for 6-11-month-old infants of all races has increased by 1.9- and 1.7-fold for boys and girls, respectively (15). These data appear to exclude sedentarity at that age as a cause of increased adiposity, but rather suggest that qualitative nutrient changes have occurred during gestation and/or lactation, and are consistent with changes in the fatty acid composition of mature breast milk and infant formulae over the past few decades. Indeed, a time-increase in LA content and/or a time-decrease in LNA content have been reported in breast milk of women living in major industrialized countries of the Western world, leading to an increase in the LA/ LNA ratio. Importantly, on a long-term basis the
ARA and DHA content of breast milk is more closely related to their dietary intake than to LA and LNA intakes. The ARA/DHA ratio has increased significantly in the past 25 years in North America, Europe and Australia, the highest values being found in the USA (16). Regarding formula milks, since 1995 manufacturers have limited the LA content and have changed that of LNA to match the ratio found in human milk to date. However, the LA content in formulae is still high and greatly variable, ranging between 10 and $30 \%$, i.e. between the adequate level and the highest level reported in breast milk (16). In adults, the daily fatty acid intake in France has increased by $40 \%$ in the past four decades. Moreover, changes in the intake of $n-6$ and n-3 PUFAs, with a striking increase in the LA/ LNA ratio, are also observed. In France, from 1960 to 2000, a disproportionate increase in the consumption of LA (2.5-fold) and ARA (2.3-fold) has been estimated. During the same period, the consumption of LNA has decreased by $40 \%$, leading to a 2.9-fold and a 4.2-fold increase in the ratios of $n-6 /$ n-3 PUFAs and LA/LNA, respectively. These profound alterations can be traced in the food chain and appear to be due to changes in human food habits as well as in the feeding pattern of breeding stock (16).

In summary, qualitative changes, acting in concert with an excess of fat intake and a positive energy balance, should have favoured excessive adipose tissue development. Since the prevention of obesity appears critical to avoid difficult if not insurmountable health problems in the future, the n-3/n-6 ratio of dietary lipids should be reconsidered from the very beginning of the food chain.

\section{References}

1. Ailhaud G. Cell surface receptors, nuclear receptors and ligands that regulate adipose tissue development. Clin Chim Acta 1999; 286: 181-90.

2. Wu Z, Xie Y, Bucher NLR, Farmer SR. Conditional ectopic expression of C/EBP $\beta$ in NIH-3T3 cells induces PPAR $\gamma$ and stimulates adipogenesis. Genes Dev 1995; 9: 2350-63.

3. Tanaka T, Yoshida N, Kishimoto T, Akira S. Defective adipocyte differentiation in mice lacking the C/EBP $\beta$ and/or C/EBP $\delta$ gene. EMBO J 1997; 24: 7432-43.

4. Rosen ED, Sarraf P, Troy AE, Bradwin G, Moore K, Milstone DS, et al. PPAR $\gamma$ is required for the differentiation of adipose tissue in vivo and in vitro. Mol Cell 1999; 4: 611-7. 
5. Barake Y, Nelson MC, Ong ES, Jones YZ, Ruiz-Lozano $\mathrm{P}$, Chien KR, et al. PPAR $\gamma$ is required for placental, cardiac and adipose tissue development. Mol Cell 1999; 4: 585-95.

6. Belmonte N, Phillips BW, Massiéra F, Villageois P, Wdziekonski B, Saint-Marc P, et al. Activation of extracellular signal-regulated kinases and CREB/ATF1 mediate the expression of CCAAT/enhancer binding proteins $\beta$ and $-\delta$ in preadipocytes. Mol Endocrinol 2001; 15: 2037-49.

7. Aubert J, Dessolin S, Belmonte N, Li M, McKenzie FR, Staccini L, et al. Leukemia inhibitory factor and its receptor promote adipocyte differentiation via the mitogen-activated protein kinase cascade. J Biol Chem 1999; 274: 24965-72.

8. Catalioto RM, Gaillard D, Maclouf J, Ailhaud G, Négrel R. Autocrine control of adipose cell differentiation by prostacyclin and $\mathrm{PGF}_{2 \alpha}$. Biochim Biophys Acta 1991; 1091: 364-9.

9. Gaillard D, Négrel R, Lagarde M, Ailhaud G. Requirement and role of arachidonic acid in the differentiation of preadipose cells. Biochem J 1989; 257: 389-97.

10. Négrel R, Gaillard D, Ailhaud G. Prostacyclin as a potent effector of adipose cell differentiation. Biochem $\mathbf{J}$ 1989; 257: 399-405.

11. Vassaux G, Gaillard D, Ailhaud G, Négrel R. Prostacyclin is a specific effector of adipose cell differentiation: its dual role as a cAMP- and $\mathrm{Ca}^{2+}$-elevating agent. J Biol Chem 1992; 267: 11092-7.

12. Massiéra F, Saint-Marc P, Seydoux J, Murata T, Kobayashi T, Narumiya S, et al. Arachidonic acid and prostacyclin signaling promote adipose tissue development: a human health concern? J Lipid Res 2003; 44: 271-9.

13. Vassaux G, Gaillard D, Darimont C, Ailhaud G, Négrel R. Differential response of preadipocytes and adipocytes to PGI2 and PGE2: physiological implications. Endocrinology 1992; 131: 2393-8.

14. Saint-Marc P, Kozak LP, Ailhaud G, Darimont C, Négrel R. Angiotensin II as a trophic factor of white adipose tissue: stimulation of adipose cell formation. Endocrinology 2001; 142: 487-92.

15. Ailhaud G, Guesnet P. Fatty acid composition of fats is an early determinant of childhood obesity: a short review and an opinion. Obes Rev 2004; 5: 21-6.

16. Ailhaud G, Massiéra F, Weill P, Legrand P, Alessandri JM, Guesnet P. Temporal changes in dietary fats: role of n-6 polyunsaturated fatty acids in excessive adipose tissue development and relationship to obesity. Prog Lipid Res 2006; 45: 203-36.

\section{Gérard Ailhaud}

CNRS UMR 6543, ISDBC

Centre de Biochimie

Faculté des Sciences

Parc Valrose

FR-06 108 Nice cedex 2

France

E-mail: ailhaud@unice.fr 